\title{
ANALYSIS OF AIRSPACE ORGANIZATION CONSIDERING AIR TRAFFIC FLOWS
}

\author{
Vaidotas Kondroška ${ }^{1}$, Jonas Stankūnas ${ }^{2}$ \\ Antanas Gustaitis' Aviation Institute, Vilnius Gediminas Technical University, \\ Rodūnios kelias 30, LT-02187 Vilnius, Lithuania \\ E-mails: ${ }^{1}$ vaidotaskondroska@ymail.com (corresponding author); ${ }^{2}$ jonas.stankunas@vgtu.lt
}

Submitted 28 February 2012; accepted 4 May 2012

\begin{abstract}
Aviation is one of the most rapidly developing types of transport playing a crucial role in the modern world. Aviation has a sensitive response to any economic or social changes and painful aviation catastrophes. In spite of increasing the flows of passengers and flights, for certain reasons, the aviation system does not always satisfy the expectations of the airspace users in the sense of efficiency. The effectiveness of air transport operations is determined by both a reduction in the costs of every airspace user and the efficiency of the air traffic management system. Airspace organization performed by the air traffic management system, i.e. its adaptation to the performance of appropriate air navigation services, largely defines the efficiency of these services. Due to various reasons, presently, the area of airspace and airspace management has remained one of the largest and incompletely used aviation resources. Beside other appropriate means, the organization of air traffic management and airspace establishes flight conditions and determines the efficiency of flight trajectories and regularity. A comparison of air traffic management systems of different regions identifies the obstacles that do not allow ensuring the maximum results of flight efficiency in any place. One of the main reasons is the high fragmentation of the specified regions that mostly coincide with the state borders. The above reasons show that in order to efficiently develop aviation, the successful development of that to the extent of one country is not enough. Thus, the best results will only be reached solving the existing problems and intended challenges to the extent of a few countries - up to the extent of the whole region. The aim of research is to define a methodology allowing the organization of regional airspace according to the flows of air traffic and subsequently enabling to solve flight efficiency problems related to air traffic management. For space evaluation, the paper suggests using rectangular grids the application of which makes possible dividing the researched space more easily and exactly. Considering the examples of air traffic management systems demonstrating the best results of efficiency, it can be exactly assumed about the number of possible airspace blocks complying with the flows of flights in the analyzed airspace. In case, a preliminary number of the wanted clusters is known, it is purposeful to apply the method of the cluster analysis of $K$-means with necessary limitations to the formed building airspace blocks and to determine the optimum version taking into account the analyzed ones. The paper suggests representing points having appropriate weighted coefficients during the stage of clustering rather than using grid cells. The optimization of the obtained airspace blocks is necessary in case the formed blocks do not properly comply with the aims raised. The application of the methodology suggested in the paper enables dividing the airspace of a big territory into airspace blocks according to the flows of flights independent from the air way network, flight intensity and the collocation of the airspace elements of a special purpose.
\end{abstract}

Keywords: air transport, airspace, airspace analysis, airspace blocks, airway network, airspace organization, grid cells, airspace layers, cluster, hierarchical analysis, methods.

\section{Introduction}

Every country has developed and maintained the systems of different kinds of transport. The aviation system is not an exception as it plays a very important role in the development of every country and region. The aviation system can be hardly imagined without an air traffic management system that enables ensuring the safety, efficiency and environmental protection of avia- tion transport. Mainly, aviation is an international type of transport, thus flights are directly influenced by air traffic management systems of different countries. The International Civil Aviation Organization (ICAO) has quite clearly specified the aviation systems and fields of air traffic management, the principles of airspace organization and procedures for airway determination. However, air traffic management systems of different countries and regions vary in their efficiency. 
Constant growth in the flows of flights requires applying new technologies in aviation and optimizing the use of airspace. Air traffic dynamics in the European region is presented in Fig. 1 (Eurocontrol 2011).

The aviation system contributes more than 134 billion EUR to the European gross local product (Legeza et al. 2010). In order to successfully develop the activity of airspace users the basis of which consists of airlines, it is not enough to reduce the costs that directly depend on them; it is also necessary to increase the efficiency of the air traffic management system ensuring straighter routes of flights and shorter delays (particularly for the aircrafts in the air) and to reduce costs for system-provided air navigation services.

A comparison of air traffic management systems of different regions, including the United States of America (USA) and Europe (conference countries of European civil aviation) shows the efficiency of air traffic management systems functioning in the territories that are similar according to their area is very different (Eurocontrol 2009). For the past few decades, the European region implementing the consistent programmes of European air traffic management has unified air traffic management systems that presently ensure the provision of safe air navigation services for an increased and still increasing number of flights. Nevertheless, its efficiency still yields to the air traffic management system of the USA providing service to the flow of aircraft exceeding it several times without any significant difficulties. One of the main differences between these air traffic management systems is the level of their fragmentation.

Airspace organization in the USA is first based on the assurance of air navigation service provision and flight efficiency to the extent of the whole country or region; meanwhile, airspace in the European region is organized according to the borders of the states and is the main reason for the existing fragmentation.

Certainly, appropriate individual means can have a positive influence on air traffic management and an increase in the efficiency of flights at the same time. However, such improvement would be insignificant or local and would not create conditions for fundamental improvement in the air traffic management system. Only a reduction in the existing fragmentation can create conditions for increasing the efficiency of flights with possible means in the whole complex to regional and local extent.

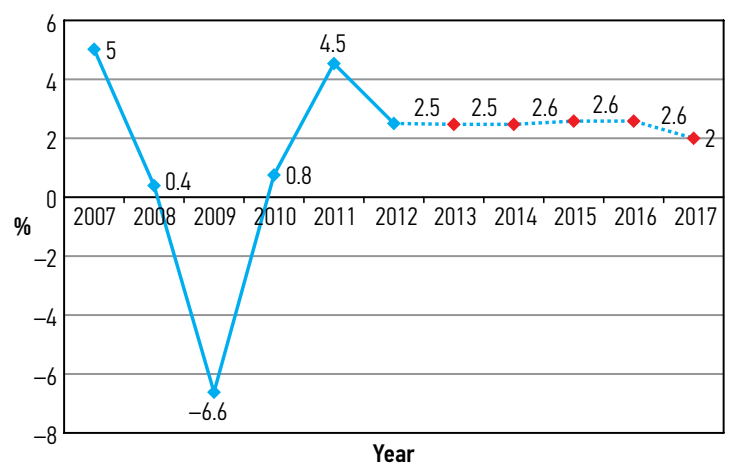

Fig. 1. Air traffic dynamics in the European region
In order to remove the obstacles related to the existing fragmentation of airspace, the projects on airspace amalgamation are performed in a number of places worldwide. One of these projects is presently being performed in the European region in order to implement the conception of the Single European Sky (SES) the aim of which is to create a few functional airspace blocks in European airspace that will help with implementing the means increasing flight efficiency. The fragmentation of airspace should also be reduced and the project on airspace amalgamation presently performed in the Russian Federation can be a domestic example; it will result in the development of 13 amalgamated airspace blocks instead of more than 100 previous airspace formations.

Obviously, it is easier to implement such projects in case they only involve the airspace of one country. In this case, only difficulties related to the technical and procedural organization of air navigation service provision, the retention of the safety level and potential changes in social conditions for the specialists working in this field may occur. In other cases, to rearrange the airspace of a few or more countries, military, land safety, tax, etc. issues should be solved besides the above-mentioned problems.

Ideally, the airspace of the whole region should be unified, but considering the peculiarities of air traffic service provision, it should be split up into a certain low number of airspace blocks developed on the functional basis and divided into the airspace of area control centre and the sectors of air traffic control at a lower level in order to implement tactical aims of air traffic service provision in that territory.

Transport is a dynamical and rapidly changing field; thus, methodologies should be developed on the scientific ground and enable efficient coordination in both strategic aims and technical and technological principles of implementation.

Nowadays, the air traffic management system in the USA is the most efficient. The scientists in Europe and the USA looking to the future are trying to analyze and search for optimal ways to organize air traffic.

\section{Principles of Airspace Organization}

Airspace organization is a difficult process that should ensure the needs of different users of airspace and a possibility of providing safe air navigation services to the maximum. In order to eliminate the existing fragmentation that negatively affects the efficiency of the air traffic management system and flights, the paper suggests performing airspace organization in two steps: first, to perform airspace organization to regional extent and apply the airspace of area control centres and air traffic control sectors according to the established structures of airspace.

Airspace organization performed by the air traffic management system, i.e. its adaptation to the performance of appropriate air navigation services, largely defines the efficiency of these services. Technological means applied in modern aviation enable using air space much more efficiently. Nevertheless, it should be 
coordinated with the functioning air traffic management system that involves both air traffic services and airspace management, including air space organization.

Airspace management services involve airspace organization and planning. Airspace is a field where flights are performed and where the efficiency of the air traffic management system and flights depends on the kind of flight performance, the principles of its organization and the formation of the elements of airspace as well as the efficiency of their later use. Thus, airspace organization is a reason for ensuring flight efficiency.

Within its limits, every state tries to develop the airway network, establish the elements of the airspace of different purposes and implement other related means so that the expectations of airspace users are satisfied. However, the efficiency of the air traffic management system is quite different in various regions.

The assurance of the throughput of airspace users and airports is a reason for the need for the air traffic management system that should create conditions for operations performed by various airspace users. The system includes, but is not limited to airlines, general aviation and military air forces.

The needs for every kind of airspace users are different starting from the required size of airspace, the period of advanced flight planning, etc.

The air traffic management system also performs the function assuring airspace throughput and the intended flow at the strategic level, constantly evaluates the throughput of the separate elements of airspace and airports and the total air traffic management system and sets appropriate limitations on the flows of flights in proper time in cases it is necessary. This function enables airspace users to apply optimum flight trajectories in this situation if required. At the tactical level, the air traffic management system should be flexible enough to be able to properly react to the conditions created and decisions made at the strategic level.

The basis of the air traffic management system involves services and the integrity of these services. Every integrated field of the air traffic management system has its purpose and the system can only function in case the common activity of all integrated functions is ensured (ICAO 2005). The optimum criteria of activities for transport should be evaluated as the accidental rather than defined ones, so that the data eliminating this factor should be taken for analysis determining the structures of airspace. The elements of the air traffic management system are presented in Fig. 2.

Airspace is a field where the air traffic management system functions. Nowadays, it involves a part of airspace from the ground to flight level 660 in the European region.

The principle of using airspace and flexible distribution among airspace users is based on the even abilities to use airspace. Thus, the structure of airspace is as follows: the elements of airspace creating conditions for ensuring different activities of airspace users and accumulating the flows of flights of different intensities are determined on the basis of airspace expectations of dif- ferent airspace users (general aviation, airlines and military air forces) and the assurance of a necessary safety level.

The principles of creating the structure of airspace are the same for more complex airspace where the main flows of the flights of different levels are performed in the region for a kind of airspace where the low-level flows of flights are performed. Only the spectrum of necessary air navigation services can be different.

In the main, the determination of airspace structure in the air traffic management system creates the first barrier assuring the prevention of possible conflict situations and the basis for performing the efficient flows of flights.

Considering the fact that the flows of flights are very complex in their nature and hard to forecast, any negative forecasted or accidental factor in one of the main flows of flights will affect the whole traffic management system in the total region and the consequences of this influence are hard to forecast and model.

The main element for the users of airspace following the assurance of safety is the efficiency of their activity. It should be noted that one of the main factors air traffic system efficiency is delays of flights reasoned by the air traffic management system or by some of its elements. Both regional and local extents are important. The latest research suggests that the mean price of a delay of an aircraft is 81 euro (Eurocontrol 2012).

While determining the structure of airspace, an important point is to ensure it creates conditions for servicing the total flow of flights without generating any delays or retaining them at the level satisfying airspace users.

The determination of airspace structure to regional extent is related to local airspace organization.

Due to a varying volume, differences between the evaluation rates of the structural efficiency of regional airspace and the evaluation rates of the efficiency of the area control centre occur.

The structure of regional airspace should create conditions for reaching the efficiency criteria of activity of the flight flow network and region, i.e. it would comply with the expectations of airspace users and ensure efficient flights. For this purpose, the structure of airspace should first be organized according to the dominating flows of flights to regional extent and then divided into the airspace of area control centres and air traffic control sectors.

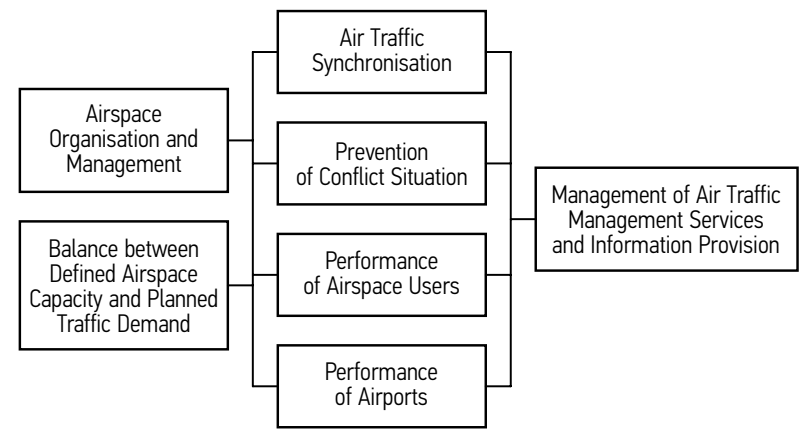

Fig. 2. Elements of the air traffic management system 
The coordinated determination of the airspace structure of both would help with reducing the fragmentation of airspace and creating conditions for performing flights from a departure to a destination airport in optimum trajectories, without any unsubstantiated regulation and delays of flight flows.

It seems that improvement on technology in transport is quite simple, however, even the most advanced means of transport can be used in an inefficient way.

It has already been tried to apply the initiatives of Functional Airspace Blocks (FAB) developed in the European region and existing FAB for certain numeral evaluation rates and flight efficiency (Eurocontrol 2008). Nevertheless, while evaluating realities and difficulties in the development of $\mathrm{FAB}$, these rates are largely oriented to the present initiatives of FAB.

\section{Latest Research}

Scientific literature has been looking for various ways of how to determine a more efficient structure of airspace. There are a number of researches in Europe, the USA and other countries analyzing the problems dealing with the efficient partitioning of airspace.

The performed analyses are based on different methods and each of them has its advantages and disadvantages. To determine the structure of airspace to regional extent and to group flight management sectors, the same criteria are suitable. Any analysis of airspace structure is usually based on a large amount of statistical or prognostic data developed on these grounds. For evaluating such big amount of data, it should be reduced performing certain average calculation. One of the most popular ways is partitioning the analysed airspace to smaller parts and the performance of appropriate research.

A number of researchers investigating airspace point to the existing airway network (Delahaye et al. 1998; Famanelli 2005) that is divided applying the method of graph division. In order to apply the methods of graph clustering widespread in other fields (Trandac et al. 2003), this method is also employed while assigning airspace. In all above discussed cases, airspace is described as an airway network rather than the volume of airspace. An example of the airway network in the European region is presented in Fig. 3.

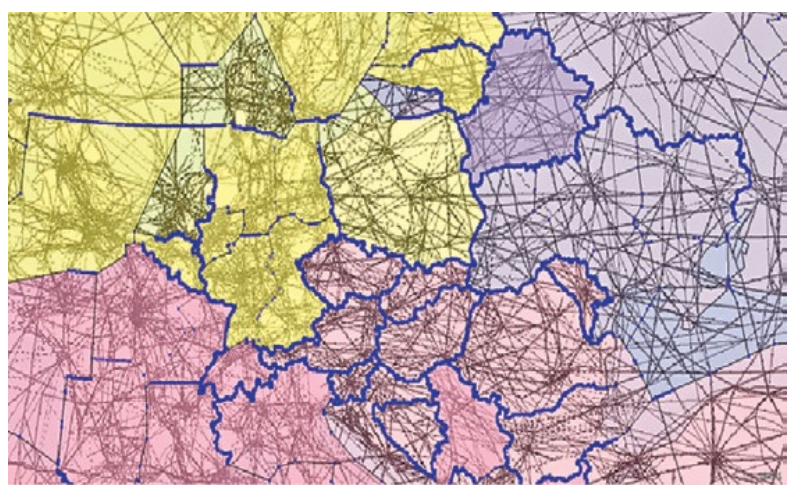

Fig. 3. The network of airways in the European region
Considering the fact that most of the flights are performed by airways, close relations between the airway network and complicated flights in a certain part of airspace appear, that is the basis for the introduced method. In case of applying the methods for partitioning airways, airspace organization is often related to the work load of an air traffic controller and determining factors as well as to a wish to minimize or harmonize flights considering the limits of air traffic control sectors. It can be reached applying an algorithm with certain limitations enabling the determination of optimal airways for air traffic control sectors.

As technology is improving, there is an increase in the number of flights a certain part of which is not performed by airways for the purpose of optimizing horizontal flight trajectories. It is evaluated in the conducted research assessing US airspace and analyzing the intersections of airways and flight routes in appropriate airspace (Mitre Corporation 2004). The application of this method creates conditions for a better evaluation of the flight distribution and work load of the air traffic controller in every air traffic control sector. Next, this method of research was also applied for using the principle of 'blank paper' airspace organization and forecasted flows of flights (Conker et al. 2007).

One of the latest researches on using the airway network and weighted-graph method was performed in order to determine a dynamical structure of airspace (Martinez et al. 2007). The method intends to make a graph of the performed flights and divide the analyzed airspace into the grid of even parts to which the determined graph of the performed flights is assigned.

The method of polygon formation by Voronoi has been also applied (Xue 2009). However, these polygons (simple and weighted) are usually formed around the peaks or segments of the airway network; thus, they retain attachment to the airway network.

The accuracy of the method based on the present airway network largely depends on the development level of the airway network in the analyzed airspace. New navigations and observation technologies ensure high accuracy, and therefore the conception of free flights is implemented more and more widely as it creates conditions for an aircraft to fly straight from the point of flying-in to the point of flying-out in such kind of airspace.

Beside the methods of airway partition, other techniques for partitioning airspace are also applied for researching airspace structure.

For performing airway analysis in US airspace and their complex, a grid made of hexagon cells was suggested (Yousefi et al. 2003). The grid cells were evaluated as air traffic control sectors and usual methods were applied in order to determine the workload of the air traffic controller in each of them.

For airspace analysis and distribution, the method can be also applied and is based on the unified amount of the flights and discretion of airspace using hexagon and tetragon grids (Klein 2005); the total number of flight messages in each cell of the grid is evaluated. While applying this method, the location of area control centres is chosen near the main airports or the main flows of 
flights and the division of airspace into area control centres is based on the even (or almost even) number of flight messages, i.e. those area control centres where flights are intensive according to the involved airspace are smaller than those where flights in airspace are less intensive. The same principle is applied for determining air traffic control sectors inside the area control centre.

\section{Methodology of Research on Airspace Organization to Regional Extent}

Considering the advantages and disadvantages of the performed research on airspace and modelling analysis to regional extent, it should be purposeful to follow the below presented main stages:

- to determine the analysed airspace in the horizontal and vertical plane;

- to choose the method for dividing airspace into constituents;

- to determine 'weight' evaluation factors for the constituents of the analyzed airspace;

- to determine requirements for grouping the integrated cells of airspace to airspace blocks;

- to determine the optimum number of formed airspace blocks and their limits in the analyzed airspace.

The methodology analyzing airspace structure applying grids and clustering is presented in Fig. 4 .

While analyzing airspace, the following issues should be emphasized:

- the analyzed airspace in the horizontal and vertical plane;

- dividing the analyzed airspace into constituents;

- determining the integrated factors evaluating the 'weight' of airspace constituents;

- determining requirements for grouping the weighted constituents of airspace into airspace blocks;

- determining the optimum number of airspace blocks and their limits in the analysed airspace.

The presented methodology for organizing the structure of airspace involves all the main stages of analysis on airspace and allows forming the most appropriate airspace blocks.

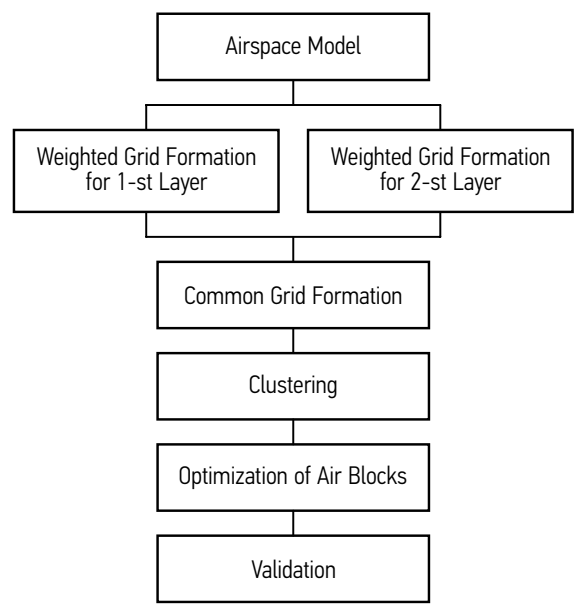

Fig. 4. The methodology analyzing airspace structure applying grids and clustering

\section{Analysis of Airspace Organization}

Aviation differs from other types of transport because an aircraft departures from an airport and reaches a destination point by air. Decisions regarding changes in the system should take into account not only the analysed object but also the processes performed within this object that could affect the criteria characterising the efficiency of these decisions (Grigorak, Shkvar 2011). A flight can relatively be divided into a few stages: taxing in the aerodrome, taking-off and landing and a flight at the cruising flight level. While taking-off and landing, the flight profile constantly changes; meanwhile, a change in the flight profile during the stage of flying at the cruising level is low. These stages of flying are different both in the peculiarities of flight performance and requirements for organizing air navigation service, which is an important point for determining airspace structures, particularly at the local level.

In order to apply aviation-implemented or intended new technologies and trying to optimize horizontal and vertical flight trajectories, airspace intended for aircraft taking-off and landing around airports is expanded.

Considering the peculiarities of the above introduced stages of flying, quite high density of airports and special purpose areas (forbidden, dangerous, restricted, temporarily segregated and military ones) at lower airspace, it should be analyzed taking into account two layers. Although airspace is relatively divided into lower and upper space at Flight Level (FL) 195 in accordance with the requirements set by the International Civil Aviation Organization (ICAO) and considering the above mentioned statements, the analysed layers of airspace should be from the ground to flight level 285 and from flight level 285 to flight level 660 (Stankūnas, Kondroška 2009). Vertical partitioning of the analysed airspace is presented in Fig. 5 .

This relative limit would separate flights at the cruising flight level from taking-off and landing flights and various aviation activities at lower airspace to the maximum.

Considering the fact, that the side limits of the upper and lower airspace of the elements (blocks) of airspace structure determined to regional extent should coincide, it should be purposeful to analyze the space in both layers, perform optimization and create unified airspace blocks.

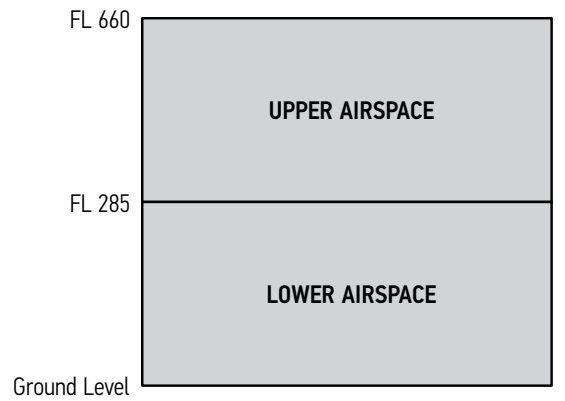

Fig. 5. The proposed division of the analysed airspace at FL 285 
Research on airspace organization shows it should be purposeful to refer to the existing airway network in the regions where the network is very dense and close to the optimum horizontal flight trajectories. Although the present airway network in the European region is quite dense, it is not ideal for various reasons and does not comply with optimum flight trajectories.

Meanwhile, the analysis of airspace division into integrated volumes does not depend on the airway network and reflects real flight trajectories.

While applying the methods of spatial analysis, it is not difficult to analyze spatial objects such as points and lines; however, it is much more difficult to analyze areas and spaces. It is sometimes possible to define variations in the analysed changes expressing mathematic functions for simple spaces, although it is often impossible or unpractical. In this case, space is often analysed in a certain discrete form.

On the grounds for making conclusions considering the first section showing that grids are often used for processing a big amount of data during the analysis of airspace, the way the grids are used for data processing will be analyzed.

One of the most exact ways of dividing airspace is the application of the grids that create conditions for dividing the researched space more easily. For conducting research, this method of division is more and more frequent. An extra advantage of using grids is a possibility of solving difficulties related with research on the limits of the investigated space.

A grid is usually a kind of means helping with preparation for further calculations. Physical space is expressed using discrete functions. Grid generation can be defined as a procedure for the regular distribution of the objects in physical space ensuring an efficient relation between the objects and presentation of all phenomena in the unified researched space in the required accuracy.

The structure of the grid, its suitability for coming up with a solution to certain tasks and the physical implementation of the solution make impact on the decision on the grid used, which is particularly important for transport. Thus, a certain choice in the shape of the grid cell depends on the geometric and physical complexity of the task solved, the method of the solution chosen, the researched space and the aims to be reached.

There are two main types of grids in the n-dimensional finite field or on the surface concept:

- a sequence of the field or surface points defined in the algorithmic way where the points are called the peaks of grids;

- the whole $n$-dimensional volumes defined in the algorithmic way involving the necessary part of the field or surface. Standard volumes are considered the grid cells.

The sides and planes of the grid cells are usually linear. Choosing a standard shape of the cell of a grating is based on their geometric simplicity and the fact that in the majority of cases the existing calculations of procedures use these cells.
There are two classes of grids: structured and nonstructured. These classes are different in the local organization of the peaks of the grid cells.

If the local structure of the peaks of the grid cells and the shape of the grid cells does not depend on their position in the sequence, but is defined by the general rule, this kind of the grid is called a structured one. If the connection of the adjacent peaks of the grid cells is different from one peak to another, this kind of the grid is called a non-structured one. As an outcome of the structured grating, the connectivity of the grid is unconditioned; meanwhile, the connectivity of the nonstructured grid should be clearly explained with the help of an appropriate procedure defining data structure.

The most efficient kind of structured grids are the grids that comply with the limits of the researched space. These grids can be generated applying various techniques and methods of grid generation. Most of these methods are specially intended for grid generation with the help of the finite differential method.

Grid generation can be defined as a procedure for the regular distribution of the objects in physical space so that an efficient relation between the objects is ensured and all phenomena are provided with proper exactness in the continuous researched space.

The application of the methods for spatial analysis is not that simple and has its own peculiarities: spatial correlation, the effect of limits to the researched space and data interrelation. The main consumption is that these measurements are independent; each object related to each object and those objects closer to each other are related more than those objects that are far from each other (Tobler 1970).

In our case, when dividing space and intending to perform related calculations, the researched Cartesian space is transformed into a kind of space where related calculations will be performed. It is helpful to choose a structured square grid where calculations are simpler.

According to its nature, airspace is connected and its cells are determined according to global geographic coordinates. Thus, airspace is related to the macroscopic fields of space and time. This property characterizes that all measurements are performed in a limited size of space and the results of these measurements are related to global coordinates.

Grid formation in the analysed airspace requires taking the dimensions of the area covered by airspace into consideration. In view that airspace organization at the regional level in order to define airspace blocks shall ensure the definition and evaluation of the main air traffic flows and activities related to the main airports, military and other zones, the dimensions of the grid cell are very important and have a direct influence on the accuracy of the research results and the complexity of calculations. The performed analysis has shown that the grid cells of the dimensions $30 \times 30$ nautical mile ensure compliance with all considerations mentioned above.

The grid generating process begins from setting right-angled two-dimensional space covering the analyzed airspace after which this set airspace is divided using the selected grid. Referring to the boundaries of the 
analyzed airspace, the grid cells related to the research area are defined and the appropriate flights of the selected period are assigned.

The researched airspace divided into volumetric grids and the use of data on real or forecasted flights in that space allow evaluating the weighted value of every cell of the grid in the researched space according to the number of performed flights. Fig. 6 analyses the airspace of the European region where functional airspace blocks will have been developed by December 2012 .

Considering the aims of research and the fact airspace is researched to regional extent, the dimensions of the chosen cell of the grating can be wider than those obtained during the analysis of the airspace of separate area control centres. Analysis to regional extent showed that the cell of a $30 \times 30$ nautical mile was chosen in airspace. Totally, 7245 cells of the grid were generated.

The division of the grid cells into the weighted classes according to the number of the performed flights allows grouping the cells into a certain number of sequences according to the requirements complying with the aim of research.

The made classification of the cells referring to appropriate classes according to the number of performed flights facilitates clustering.

For the analysis of airspace, data collected on 1 July 2011 (the most intensive day in the European region in 2011) was used.

The generated cells of the grid were divided into 6 classes according to their weight:

- Class 1 - cells of the grid where no flights take place;

- Class 2 - cells from 1 till 20 flights;

- Class 3 - cells from 20 till 50 flights;

- Class 4 - cells from 50 till 100 flights;

- Class 5 - cells from 100 till 200 flights;

- Class 6 - cells with 200 flights and more.

The distribution of the grid cells in the researched airspace according to their weighted classes is shown in Fig. 7.

One of the most important factors is compliance with the main flows of flights. When evaluating the distribution of the weighted cells of the grids in the researched airspace, it would be effective to assume that all grid cells are assigned to the main flows where over 50 flights a day are performed. There are a big number of cells where no flights have been performed. Different colours were assigned to each class of the cells. Following the evaluation and classification of the weight of the grid cells, it is possible to operate a two-dimensional rather than a three-dimensional square grid during research, which facilitates further calculations. An example of two-dimensional grid cells in the researched space assigned to different classes is presented in Fig. 8.

After the evaluation of both airspace layers, a common grid representing both lower and upper airspace is generated.

It is to mention that if the grid of upper airspace only evaluates the performed flights, the grid representing lower airspace evaluates aerodromes and terminal airspace around them, the airspace zones of special purpose and their buffer zones.

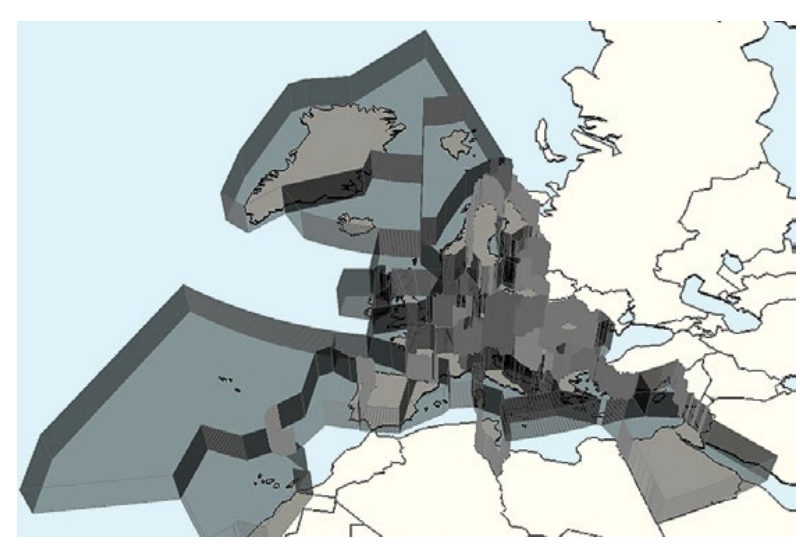

Fig. 6. The analysed airspace

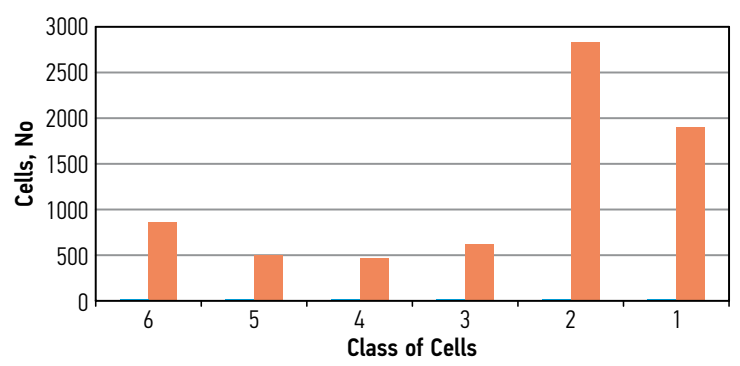

Fig. 7. The distribution of the grid cells to weighted classes

\begin{tabular}{|l|l|l|l|l|l|}
\hline 2 & 3 & 2 & 3 & 2 & 3 \\
\hline 4 & 1 & 2 & 2 & 2 & 1 \\
\hline 4 & 1 & 1 & 6 & 2 & 1 \\
\hline 2 & 1 & 5 & 6 & 4 & 2 \\
\hline 2 & 2 & 5 & 2 & 3 & 2 \\
\hline 1 & 3 & 3 & 2 & 1 & 1 \\
\hline
\end{tabular}

Fig. 8. An example of two-dimensional grid cells in the researched space assigned to different classes

The common grid includes the weighted coefficients of the layers of the analysed airspace and is a reason for connecting the cells of this grid to the formed airspace blocks.

The generation process is presented in Fig. 9.

Having classified the grid cells, they are grouped into a certain number of sequences according to the requirements complying with the aim of research.

Grouping similar objects into appropriate categories is performed conducting cluster analysis. To reach certain aims of research, dividing available or research data into meaningful compounds should be intended. Thus, the main aim of cluster analysis is the division of different objects into groups (clusters) according to their maximum similarity and differences from other groups. 


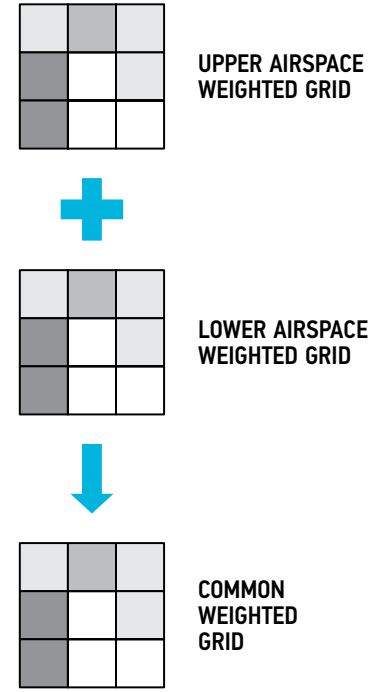

Fig. 9. The generation process of a common grid

Cluster analysis is quite detailed and may vary when applied in different fields. During grouping, every cluster is defined by its constituents and centroid. The centroid of the cluster is the point to which the sum of its constituents is the lowest. Usually, two methods - hierarchical and non-hierarchical - are used for cluster analysis: (Anderberg 1973). Hierarchical methods of cluster analysis are employed to the structures of a few levels and do not allow regrouping the already grouped objects (Johnson, Wichern 2007).

The hierarchical method of cluster analysis assumes all data forms of one big cluster; in turn, this one consists of smaller ones and the latter ones - from even smaller ones. The hierarchical methods of cluster analysis are divided into agglomerative or divisive methods.

While applying the agglomerative method of hierarchical analysis, similar separate clusters are gradually connected to each other on the basis of certain rules as long as the common cluster is obtained. Besides, while applying the hierarchical methods of cluster analysis, no possibility of regrouping the objects grouped in the previous steps occurs.

While applying the divisive method of hierarchical analysis, work is done in the opposite direction, i.e. starts from one cluster and it is divided into two clusters during each step as long as every object forms a separate cluster.

Non-hierarchical methods are mostly applied in case the number of clusters is known or chosen in advance. The non-hierarchical method of cluster analysis is represented by the method of $K$-means. In order to apply this method and avoid local minimums and false classification, the number of desired clusters should be chosen very prudently.

During data division, the non-hierarchical methods of cluster analysis mainly form clusters to non-overlapping groups without any hierarchical relation between them. While applying these methods, data is grouped into $\mathrm{k}$ of the clusters where $\mathrm{k}$ is determined in advance or obtained during the process. The non-hierarchical methods of cluster analysis are different from the hierarchical ones as non-hierarchical one-level solutions are obtained. Therefore it is possible to correct the process by regrouping objects and apply them to much bigger data sequences.

At the same time, the hierarchical methods of cluster analysis lead to some even structures and do not allow regrouping the objects grouped before. The method of $K$-means is one of the most popular non-hierarchical methods of cluster analysis.

The clustering algorithms based on the grids such as STING or CLIQUE do not fully comply with the principles establishing the structure of airspace.

During clustering, we propose using not the grid cells but representing points with appropriate weighted coefficients. A square cell of the grid is also defined using four peaks in two-dimensional space. It is possible to choose one of the peaks of the grid cell or centroid as a representing point. While analysing the structure of airspace to regional extent, the centroid of the cell is better to use.

Choosing the attributes and their number depends on the researched space. The data used for clustering should be defined according to its characteristics, attributes, classes, etc. The whole of all these properties is the attributes of the task solved. The use of largely correlated attributes does not allow properly noticing differences in desired data; meanwhile, the use of very different attributes of the analysed data without any influence on the analysed task can only distort the obtained results. Thus, there is no purpose to overload the applied model with the number of the attributes used.

The non-hierarchical methods of cluster analysis usually require lower program capacities than the hierarchical ones as the only one variant of clusters should be formed.

Considering the examples of the above discussed air traffic management systems showing the best results of efficiency and the number of the initiatives of functional airspace blocks in the European region, we could make an assumption, that a region similar to the European one should have no more than 9 airspace blocks (this number may even be too high).

In case of knowing the preliminary number of desired clusters, it is useful to apply the method of the cluster analysis of $K$-means (MacQueen 1967) by giving appropriate limitations to the formation of clusters.

The method of $K$-means evaluates every point as an object with a place in space. The objects are grouped so that they are located one next to the other in every cluster as close as possible and as far from the objects of other clusters as possible. The limitations applied to clustering should ensure the implementation of the aims of the task solved.

While applying cluster analysis, similarities should be measured taking into account every combination of the clustered objects. During measurement, interrelation between the criteria of cluster analysis can be noticed; although the results of certain measurements can be equal according to one criterion, they can be complete- 
ly different considering other aspects. A good result of clustering can be only obtained after choosing suitable attributes to the task definition, data transformation and measurements of similarities.

A crucial point is the application of the following criteria for analyzing the airspace and formation of airspace blocks to regional extent:

- the side limits of the upper airspace of airspace blocks should coincide with the side limits of the lower airspace of these blocks;

- each cell of the grid can only belong to one airspace block (assurance of integrity);

- all cells of one created block should be interconnected so that it is possible to get from the cells forming any airspace block via other cells of this airspace block to any other cell of the same airspace block (assurance of consistence);

- the balance of the territory occupied by the formed airspace blocks (difference between the formed blocks cannot exceed 30\%);

- every formed air space block should be concentrated in one place to the maximum and cannot contain any narrow branches (assurance of concentration);

- the limit between the formed airspace blocks should pass the minimum number of the cells of the main flight-representing grid (compliance with the main flows of flights);

- every airport with the assigned airspace and special purpose airspace zones as well as the buffer airspace can only belong to one airspace block;

- to avoid any negative influence on the intended airspace blocks in the analysed airspace caused by insignificant changes in the main flows of flights, the minimum 50 nautical mile interval between the main flows of aircrafts and the limit of the adjacent airspace blocks should be established during the stage creating any airspace block;

- to reach the maximum effect, no more than 9 airspace blocks should be formed in the airspace of the analysed size in relation with the advantages given by airspace amalgamation.

Depending on the aims of work, more criteria are possible; however, they should be thoroughly selected. The optimization of the obtained airspace blocks is necessary if the formed airspace blocks do not fully comply with the raised aims. In this case, optimization is performed applying optimization algorithms.

\section{Conclusions}

1. Although airspace organization is constantly improved, it is not possible to solve all the problems in the field to the extent of one state.

2. The examples of the countries having a big area show that the present airspace fragmentation according to the state borders is one of the essential obstacles to ensure more efficient flights, so that airspace organization to regional extent, including the implementation of other means - should be one of the underlying trends of changes in air traffic management.
3. The attachment to the existing airway network does not evaluate any real horizontal flight trajectories; it is possible to perform it with the help of the grating and the best choice would be the structured square.

4. While performing the calculations of grouping grid sequences, the centroids of the weighted cells of grids should be used.

5. At the stage of clustering, the application of the cluster analysis method of $K$-means with established limitations quite exactly enables performing airspace organization to regional extent.

6. The application of the criteria suggested for airspace organization to regional extent allows establishing a really possible regional airspace amalgamation model based on compliance with the flows of flights.

7. The structure of airspace to regional extent formed on the grounds for this methodology much better complies with the horizontal trajectories of the main flows of flights in the region and creates conditions for more efficient flights.

8. The application of the suggested methodology allows partitioning various airspaces covering huge territories independent from the airway network, flight intensity and the collocation of the elements used in airspace for special purposes.

\section{References}

Anderberg, M. R. 1973. Cluster Analysis for Applications. Academic Press. 359 p.

Conker, R. S.; Moch-Mooney, D. A.; Niedringhaus, W. P.; Simmons, B. T. 2007. New process for 'clean sheet airspace design and evaluation', in Proceedings of the 7th USA/Europe Air Traffic Management Research and Development Seminar. 2-5 July 2007, Barcelona, Spain. 10 p. Available from Internet: http://www.atmseminar.org/seminarContent/ seminar7/papers/p_091_DAM.pdf

Delahaye, D.; Schoenauer, M.; Alliot, J.-M. 1998. Airspace sectoring by evolutionary computation, in 1998 IEEE International Conference on Evolutionary Computation Proceedings. IEEE World Congress on Computational Intelligence. 4-8 May 1998, Anchorage, AK. 218-223. http://dx.doi.org/10.1109/ICEC.1998.699504

Eurocontrol. 2008. Evaluation of Functional Airspace Block (FAB) Initiatives and Their Contribution to Performance Improvement. 240 p. Available from Internet: http://ec.europa. eu/transport/air/studies/doc/traffic_management/evaluation_of_fabs_final_report.pdf

Eurocontrol. 2009. U.S./Europe Comparison of ATM-related Operational Performance. 64 p. Available from Internet: https://www.eurocontrol.int/sites/default/files/content/ documents/single-sky/pru/publications/other/us-europecomparison-of-atm-related-operational-performance.pdf

Eurocontrol. 2011. Medium-Term Forecast. STATFOR Doc442. $21 \mathrm{p}$.

Eurocontrol. 2012. ATM Cost-Effectiveness (ACE) 2010 Benchmarking Report with 2011-2015 Outlook. 165 p. Available from Internet: http://www.eurocontrol.int/sites/default/ files/content/documents/single-sky/pru/publications/ace/ ace-2010-benchmarking-report-and-outlook.pdf

Famanelli, D. 2005. A K-Partitioning Algorithm for Airspace Sectorization. Tesi Di Laurea. Università Degli Studi Di 
Padova. 149 p. Available from Internet: http://www.eurocontrol.int/crds/gallery/content/public/thesis/6130-CRDSRNDUNV-FAM.pdf

Grigorak, M.; Shkvar, O. 2011. A logistic approach for description of decision-making process, Aviation 15(1): 21-24. http://dx.doi.org/10.3846/16487788.2011.566316

ICAO. 2005. Global Air Traffic Management Operational Concept. Doc 9854, AN/458. International Civil Aviation Organization. 82 p. Available from Internet: http://www.icao. int/Meetings/anconf12/Documents/9854_cons_en[1].pdf

Johnson, R. A.; Wichern, D. W. 2007. Applied Multivariate Statistical Analysis. 6th edition. Prentice Hall. 800 p.

Klein, A. 2005. An efficient method for airspace analysis and partitioning based on equalized traffic mass, in Proceedings of the 6th USA/Europe Air Traffic Management Research and Development Seminar. 27-30 June 2005, Baltimore, Maryland, USA. 10 p. Available from Internet: http://www. atmseminar.org/seminarContent/seminar6/papers/p_001_ AEM.pdf

Legeza, E.; Selymes, P.; Torok, A. 2010. Investigation of European air transport traffic by utility-based decision model, Aviation 14(3): 90-94.

http://dx.doi.org/10.3846/aviation.2010.14

MacQueen, J. B. 1967. Some methods for classification and analysis of multivariate observations, in Proceedings of the fifth Berkeley Symposium on Mathematical Statistics and Probability, University of California Press, Vol. 1, 281-297.

Martinez, S. A.; Chatterji, G. B.; Sun, D.; Bayen, A. M. 2007. A weighted-graph approach for dynamic airspace configuration, in AIAA Guidance, Navigation and Control Conference and Exhibit. 20-23 August 2007, Hilton Head, South Carolina. Available from Internet: http://web.ics.purdue. edu/ dsun/pubs/gnc07.pdf

Mitre Corporation 2004. Intersect Density Analysis Toolset (IDAT). Available from Internet: http://www.caasd.org/ work/project_details.cfm?item_id=134

Stankūnas, J.; Kondroška, V. 2009. Oro erdvès modeliavimas makroskopiniu lygiu, Mokslas - Lietuvos ateitis [Science Future of Lithuania] 1(6): 115-119 (in Lithuanian).

http://dx.doi.org/10.3846/mla.2009.6.24

Tobler, W. R. 1970. A computer movie simulating urban growth in the Detroit region, Economic Geography 46(2): 234-240.

Trandac, H.; Baptiste, P.; Duong, V. 2003. Optimized sectorization of airspace with constraints, in Proceedings of the 5th USA/Europe Air Traffic Management Research and Development Seminar. 23-27 June 2003, Budapest, Hungary. 11 p. Available from Internet: http://www.atmseminar.org/ seminarContent/seminar5/papers/p_071_TFO.pdf

Xue, M. 2009. Airspace sector redesign based on Voronoi diagrams, Journal of Aerospace Computing, Information, and Communication 6(12): 624-634. http://dx.doi.org/10.2514/1.41159

Yousefi, A.; Donohue, G. L.; Qureshi, K. M. 2003. Investigation of enroute metrics for model validation and airspace design using TAAM, in Proceedings of the 5th USA/Europe Air Traffic Management Research and Development Seminar. 23-27 June 2003, Budapest, Hungary. 10 p. Available from Internet: http://www.atmseminar.org/seminarContent/seminar5/papers/p_058_MPM.pdf 